\title{
POR UMA ANÁLISE MORFOSSINTÁTICA PARA A POSIÇÃO DOS SUJEITOS PRÉ-VERBAIS NO PORTUGUÊS BRASILEIRO E NO PORTUGUÊS EUROPEU
}

\author{
Cláudia Roberta Tavares Silva ${ }^{(*)}$ \\ Universidade Federal de Alagoas
}

RESUMO: Neste artigo, tenho como objetivo precípuo argumentar a favor da idéia de que sujeitos pré-verbais no Português Brasileiro (PB) e no Português Europeu (PE) estão ocupando a posição-A Spec, AgrSP, uma análise que contraria a proposta de eles estarem deslocados à esquerda conforme defendem Barbosa (1996), Barbosa; Duarte; Kato (2001), dentre outros. Ademais, tomando por base a pesquisa desenvolvida por Costa e Galves (2002), apresentarei evidências de que tanto no $\mathrm{PB}$ quanto no $\mathrm{PE}$ há movimento curto do verbo, ao contrário de línguas como o francês. Nessa acepção, estando os sujeitos pré-verbais em ambas as línguas na posição mais alta da frase e tendo o verbo se movido até $\mathrm{T}$, há motivação para que a componente morfológica atue sobre as derivações sintáticas. Para tanto, a análise encontra-se fundamentada no quadro teórico da Morfologia Distribuída (HALLE; MARANTZ, 1993; BOBALJIK, 1995).

PALAVRAS-CHAVE: Posição dos sujeitos pré-verbais; movimento do verbo; morfologia verbal

\section{Introdução}

Neste trabalho' tenho por finalidade, por um lado, discutir a posição dos sujeitos pré-verbais no $\mathrm{PB}$ e no $\mathrm{PE}$, a fim de evidenciar que eles estão na posição mais alta da estrutura frásica, nomeadamente Spec, AgrSP, não sendo Spec, TP licenciado nos contextos declarativos finitos submetidos à análise por razões relacionadas à morfologia flexional nessas línguas tal como ocorre no inglês (BOBALJIK, 1995), uma situação que contraria a generalização de que sujeitos pré-verbais nessas línguas estão deslocados à esquerda,

1 Esta pesquisa foi financiada por uma bolsa da CAPES durante o curso de doutoramento 
sendo duplicados por uma categoria pronominal (BARBOSA, 1996; COSTA; GALVES, 2002; BRITTO, 2000; BARBOSA; DUARTE; KATO, 2001, dentre outros). Por outro, com base no quadro teórico da Morfologia Distribuída, argumentarei a favor da existência de movimento pós-sintático na componente morfológica da gramática dessas línguas, nomeadamente, Lowering de Agr-para-T.

Com base no exposto acima, duas predições erguem-se da análise aqui desenvolvida: a) o parâmetro EPP formulado por Alexiadou e Anagnostopoulou (1998) não ganha suporte empírico quando se observa que sujeitos pré-verbais ocupam Spec, AgrSP no $\mathrm{PE}$, uma língua pro-drop prototípica, o que me leva a assumir, ao contrário dessas autoras, que o traço EPP da categoria AGR é checado por Move ou Merge de um DP e não pelo movimento do verbo e b) o caráter "defectivo" de Agr na gramática do PB parece estar relacionado à morfologia flexional que tem se tornado inerte à identificação de sujeitos nulos referenciais e não diretamente ao fato de essa categoria possuir o traço-D fraco, tendo em vista que Move ou Merge de um DP no Spec dessa categoria funcional é licenciado tal como ocorre no inglês.

Em suma, na seção 2, apresentarei argumentos que favorecem a existência do movimento curto de $\mathrm{V}$-para-T na gramática do $\mathrm{PB}$ e do PE, tomando por base a análise de Costa e Galves (2002); na seção 3, analisarei a posição dos sujeitos pré-verbais em ambas as línguas onde não só discorrerei sobre algumas análises que assumem o fato de esses sujeitos estarem deslocados à esquerda, como também apresentarei contra-evidências às mesmas e, por fim, na seção 4 , apresentarei as conclusões depreendidas ao longo da análise.

\section{Evidências para movimento curto de $V$-para- $\mathbb{T}$ na gramática do Português Brasileiro e do Português Europeu}

Pollock (1989), ao observar o comportamento assimétrico entre o inglês e o francês no que se refere à posição de advérbios de VP como "freqüentemente" ((souvent (francês), often (inglês)) e de quantificadores flutuantes como "todos" ((tous (francês), all (inglês)), chega a concluir que a primeira língua não possui movimento de Vpara-I na sintaxe, ao contrário da segunda. Uma das evidências encontradas pelo autor é que nas sentenças declarativas do inglês esses advérbios e quantificadores não podem romper a adjacência entre o 
verbo e o seu complemento, ao passo que no francês é obrigatória a não-adjacência entre esses constituintes, o que implica considerar que o verbo se move para fora do VP. Vejam-se, portanto, as seguintes frases:

(1)a. *John kisses often Mary.

"O João beija frequentemente a Maria."

b. Jean embrasse souvent Marie.

"O João beija freqüentemente Maria."

c. John often kisses Mary.

"O João freqüentemente beija a Maria."

d. *Jean souvent embrasse Marie.

"O João frequientemente beija a Maria."

(2)a. *My friends love all Mary.

"Meus amigos amam todos a Maria."

b. Mes amis aiment tous Marie.

c. "Meus amigos amam todos a Maria."

My friends all love Mary.

"Meus amigos todos amam a Maria."

d.*Mes amis tous aiment Marie.

"Meus amigos todos amam a Maria."

(POLLOCK, 1989, p. 367)

Contrariamente à proposta de Pollock que estabelece associação entre Agr transparente e movimento do verbo, sendo este a causa da riqueza morfológica do núcleo flexional numa língua como o francês, Vikner (1997) argumenta que o movimento do verbo nas línguas particulares é consequiência da riqueza morfológica da flexão verbal. Para tanto, ao rediscutir as diversas propostas de análises que se embasam no fato de a morfologia flexional rica ser o fator desencadeador do movimento do verbo e, com base na análise de paradigmas flexionais em diversas línguas, o autor chega à formulação da seguinte generalização:

(3) Movimento de $V^{\circ}$-para- $I^{\circ}$ se e somente se todos os tempos são flexionados para pessoa.

Assumindo nesta pesquisa a generalização em (3) de que morfologia rica que motiva o movimento do verbo está relacionada à morfologia de pessoa presente em todos os tempos verbais, é plausível assumir, tomando por base os paradigmas flexionais do $\mathrm{PB}$ e do $\mathrm{PE}$ 
conjugados no presente e no pretérito, que a morfologia flexional relacionada a esse movimento é rica em ambas as línguas em virtude de haver morfologia de pessoa nesses tempos verbais. Nessa acepção, analisando as frases declarativas do $\mathrm{PB}$ e do $\mathrm{PE}$, a seguir, extraídas de Costa e Galves (2002, p. 111), corrobora-se a análise de Vikner (1997): advérbios de VP e quantificadores flutuantes podem ocorrer entre o verbo e o seu complemento, o que serve de evidência empírica, à semelhança do francês, de que o verbo se move para fora do VP:

(4)a. O João beija frequientemente a Maria.

b.As crianças beijam todas a Maria.

(5)a. Jean embrasse souvent Marie.

"O João beija freqüentemente Maria."

b.Mes amis aiment tous Marie.

"Meus amigos amam todos a Maria."

Não obstante, o PB e o PE permitem que o advérbio freqüentemente e o quantificador flutuante todas rompam a adjacência entre o sujeito e o verbo (cf. (6)), ao contrário do francês (cf. (7)):

(6) a. O João freqüentemente beija a Maria.

b. As crianças todas beijam a Maria.

(7) a.*Jean souvent embrasse Marie.

"O João frequientemente beija a Maria."

b.*Mes amis tous aiment Marie.

"Meus amigos todos amam a Maria."

Com base na assimetria acima, poder-se-ia pensar, à primeira vista, que a possibilidade de o advérbio e o quantificador flutuante ora ocuparem a posição pré-verbal (cf. (6)), ora a posição pós-verbal (cf. (4)) seria evidência de que o movimento de V-para-I na gramática do PB e do PE é opcional, no entanto, Costa e Galves (op. cit., p. 112) apresentam argumentos convincentes à não-opcionalidade:

a) posição de advérbios como bem e atentamente só são legitimados em posição pós-verbal:

(8) a. *O Pedro bem/ atentamente leu o livro.

a'.O Pedro leu bem/ atentamente o livro.

b) posição distinta para advérbios que são ambíguos entre uma leitura de modo e uma leitura orientada para o sujeito: 
(9) a.O Pedro atentamente leu o livro. (Orientado para o sujeito/ *Modo)

b. O Pedro leu atentamente o livro. (*Orientado para o sujeito/ Modo)

Portanto, a partir dos dados de (8) e (9), sou levada a assumir com Costa e Galves (2002) que o movimento do verbo é obrigatório na gramática do $\mathrm{PB}$ e do $\mathrm{PE}$. Adotando a cisão da categoria funcional IP em AgrP e TP, a questão que se ergue é saber para que núcleo flexional o verbo se move nessas línguas, se para Agr, à semelhança do francês, ou para $T$.

Costa e Galves observam, por um lado, que no $\mathrm{PB}$ e no $\mathrm{PE}$ advérbios, como inteligentemente, quando possuem leitura orientada para o sujeito, necessariamente rompem a adjacência entre o sujeito e o verbo nessas línguas (cf. (10a)), ao passo que, possuindo esse mesmo advérbio leitura de modo, ele deve seguir o verbo (cf. (10b)). Por outro lado, esse tipo de advérbio, ao romper a adjacência entre o verbo e o objeto no francês, possui os dois tipos de leitura indistintamente (cf. (11)):

(10) a. O Pedro inteligentemente leu o livro. (leitura orientada para o sujeito/ *leitura de modo)

b. O Pedro leu inteligentemente o livro. (*leitura orientada para o sujeito/ leitura de modo)

(11) Pierre lit intelligemment le livre. (leitura orientada para o sujeito/ leitura de modo)

(COSTA; GALVES, op. cit., p. 112-113)

Assumindo com Costa (1998) que advérbios com leitura orientada para o sujeito estão adjungidos à projeção TP e que advérbios de modo estão adjungidos ao VP, fica evidenciado que em (10a) o verbo se move até o núcleo $\mathrm{T}$, estando o advérbio orientado para o sujeito em adjunção a TP. Já no francês, tendo em vista a ambigüidade entre a leitura de orientação para o sujeito e a leitura de modo do advérbio, o verbo encontra-se em Agr.

Evidência adicional para o movimento curto do verbo no PB e no $\mathrm{PE}$ tem a ver com a assimetria constatada entre essas línguas e o italiano. Nessa última, Costa e Galves, citando Belletti (1990), observam que quantificadores indefinidos como Nessuno ("ninguém") 
só podem ser legítimos na posição pré-verbal se recebem uma entoação especial $^{2}$. Não obstante, no PB e no PE, esses quantificadores não estão submetidos a esse tipo de restrição. A falta de adjacência atestada em ambas as línguas difere da que é encontrada no italiano. Nessas línguas, advérbios, como provavelmente e possivelmente, podem romper a adjacência entre o sujeito e o verbo (cf. (12)), ao contrário do italiano (cf. (13)):

(12) Ninguém provavelmente falhou.

(13) *Nessuno probabilmente ha sbagliato. "Ninguém provavelmente falhou."

(COSTA; GALVES, 2002, p. 111)

Portanto, se o verbo pára em T no PB e no PE, fica explicada, por um lado, a falta de adjacência entre o sujeito e o verbo em (12) e em (10a), bem como fica evidenciado que o traço-V de $\mathrm{T}$ é forte em ambas as línguas. No francês, por outro lado, o traço-V de Agr é forte e, portanto, o verbo sobe até esse núcleo funcional para a verificação desse traço.

3. Por uma análise dos sujeitos pré-verbais no português brasileiro e no português europeu

Analisando a posição dos sujeitos pré-verbais em línguas de sujeito nulo, em específico, nas línguas românicas, Barbosa (1996) assume que a real posição argumental para os sujeitos é Spec, VP, posição onde são gerados, sendo a posição pré-verbal uma posição não-A, tendo em vista os sujeitos ou estarem deslocados à esquerda, ou sofrerem movimento-A' para uma posição relacionada com Foco. As evidências encontradas pela autora baseiam-se em dois dialetos do norte da Itália: o trentino e o fiorentino que possuem clíticos sujeitos, além dos sujeitos que se encontram deslocados à esquerda. Tal proposta implica considerar, portanto, que os sujeitos pré-verbais em línguas não-pro-drop, como o inglês e o francês, ocupam a posição-A, nomeadamente Spec, $\mathrm{IP}^{3}$, e que a ordem SVO atestada nas línguas pro-drop consiste ou de construções com Deslocamento à Esquerda

Para uma análise similar, ver Barbosa (1996).

Neste artigo só farei menção às categorias AgrP e TP quando necessário. 
Clítica (Clitic Left Dislocation (CLLD)) ou do movimento do sujeito para o Spec de uma categoria funcional relacionada com foco, nomeadamente Spec, CP.

Partindo do acima exposto, a autora assume que, nos casos de inversão sujeito-verbo numa língua como o italiano, Spec, IP é preenchido por um expletivo nulo (pro) à semelhança de Rizzi (1997), havendo o movimento do verbo até I e permanecendo o sujeito em sua posição de base, Spec, VP (cf. (14a')). Nos casos da ordem SVO, duas situações podem ser depreendidas: a) o sujeito encontra-se deslocado à esquerda numa posição de adjunção à categoria máxima IP, sendo duplicado por um pro na posição Spec, IP, havendo movimento de Vpara-I (cf. (15a')) e b) o sujeito ocupa Spec, CP nos contextos de focalização via movimento-A' e o verbo move-se até o núcleo dessa categoria funcional (cf. (16a')):

(14) a. Telefona Gianni.

$a^{\prime}$. [IP pro (expletive) [r telefona [VP Gianni t]]]

(15) a. Gianni telefona.

a'. [IP Gianni $\mathrm{i}_{\mathrm{i}}$ IP $_{\text {Pro }}$ telefona ....]]

(16) a. GIANNI telefona.

$a^{\prime}$. [CP GIANNI [C, telefona $\left.\left.t\right]\right]$

(BARBOSA, op. cit., p. 376)

A fim de fundamentar sua proposta de análise para a distinção entre línguas pro-drop e não-pro-drop no que se refere à posição estrutural dos sujeitos pré-verbais, a autora retoma estruturas frásicas do fiorentino (doravante $\mathrm{F}$ ) e do trentino (doravante $\mathrm{T}$ ) em que clíticos sujeitos devem ser foneticamente realizados nesses dois dialetos (ex: *(Tu) parli (F) “*(você) fala."; *(Te) parli (T) "*(você) fala."), ao contrário do que acontece no italiano standard, que não possui clíticos sujeitos, mas permite sujeitos nulos referenciais (ex. Parli "(você) fala").

Seguindo o viés argumentativo de Barbosa, Alexiadou e Anagnostopoulou (1998) assumem que nas línguas pro-drop a única posição-A para os sujeitos é, de fato, Spec, VP, estando os sujeitos pré-verbais deslocados à esquerda, o que caracteriza uma construção CLLD. Essas autoras propõem que a checagem do traço EPP que é universalmente forte dá-se de forma diferenciada em línguas pro-drop, como o grego, o italiano e o espanhol, e em línguas não-pro-drop, 
como o francês e o inglês. Nas primeiras, esse traço é checado por Move ou Merge de um $\mathrm{X}^{\circ}$ (línguas EPP-fracas), ao passo que nas últimas sob Move ou Merge de um XP (línguas EPP-fortes), o que implica considerar que, nessas últimas, os DPs sujeitos têm propriedades-A. Ademais, é assumido que nestas últimas o traço-D forte (ou melhor, o traço EPP) força a presença de um XP no Spec, AgrSP, a fim de o traço dessa categoria ser checado. Do contrário, em línguas pro-drop, Spec, AgrSP não precisa ser projetado, tendo em vista os sujeitos pré-verbais terem propriedades-A'. Sob a existência desse parâmetro, essas autoras defendem que línguas pro-drop, como o grego, têm a possibilidade de checar o traço EPP através dos afixos de concordância que ocorrem no verbo, os quais tem o status categorial de um pronome ${ }^{4}$ em virtude de incluir "a nominal element $([+\mathrm{D},+$ interpretable phi-features, potentially +Case $]$ " (ALEXIADOU; ANAGNOSTOPOULOU, op. cit., p. 516) ${ }^{5}$.

Tomando por base os dois dialetos italianos, o trentino e o fiorentino, as autoras também argumentam que, sendo línguas de sujeito nulo, a checagem do traço EPP não pode dar-se via Merge/Move de um XP, mas através de um elemento $\mathrm{X}^{\circ}$ inserido no núcleo AgrS que corresponde, nesses casos, ao clítico sujeito. Argumentando que não há expletivos nulos na ordem VSO em línguas pro-drop na posição Spec, IP, é proposto também pelas autoras que a checagem do traço EPP da categoria AgrSP dá-se via movimento do verbo para o núcleo dessa categoria funcional, tendo em vista os afixos de concordância possuírem uma natureza pronominal.

\subsection{Sujeitos pré-verbais estão deslocados à esquerda no português brasileiro}

Tem sido sobejamente assumido que sujeitos pré-verbais no $\mathrm{PB}$ estão deslocados à esquerda (BARBOSA; DUARTE; KATO, 2001; DUARTE, 2000; BRITTO, 2000; KATO, 2000; COSTA; GALVES,

${ }^{4}$ Alexiadou e Anagnostopoulou (1998, p. 531) propõem: "the AGR affix actually replaces the subject DP in its EPP-licensing capacity" ( $O$ afixo AGR realmente substitui o DP sujeito em sua capacidade de licenciar o EPP. - Tradução minha).

${ }^{5}$ Um elemento nominal ( $[+\mathrm{D}$, +traços-phi interpretáveis, +Caso potencialmente] - Tradução minha. 
2002, dentre outros.). Umas das evidências para essa análise baseia-se no fato de as construções com duplicação do sujeito serem bastante produtivas no $\mathrm{PB}$, as quais consistem na duplicação desse constituinte por um pronome resumptivo co-referente nulo ou preenchido em Spec, TP quer em sentenças principais, quer em sentenças subordinadas, podendo haver ou não um corte entoacional, bem como outros constituintes que intervenham entre eles:

(17) Eu acho que um trabalho sério ${ }_{i}$ ele $_{i}$ teria que começar por aí.

(18) Você $\mathrm{i}$, no Canadá, você pode ser o que quiser.

(DUARTE, op. cit, p. 28-29)

Ao contrário do $\mathrm{PB}$, construções com sujeitos pré-verbais deslocados à esquerda são marcadas no PE. Os sujeitos dessas construções necessitam de uma interpretação de foco, não podendo haver adjacência sintática entre eles e o pronome resumptivo e, ainda, a presença de um corte entoacional é obrigatória:

(19)a.O João... ele estupidamente entornou o café.

b.A: Quem foi à praia?

(COSTA, 2003, p. 39)

B: O Pedro...ele foi, os outros não sei.

(COSTA; GALVES, 2002, p. 119)

Além do contexto marcado ao qual os sujeitos deslocados em PE estão submetidos, sentenças subordinadas com sujeitos deslocados à esquerda não são produzidas pela gramática dessa língua (cf. (20)). Contudo, como atestam Costa e Galves, a posição pós-verbal está disponível ao pronome resumptivo nessa gramática, ao contrário da gramática do $\mathrm{PB}$ que não produz inversão sujeito-verbo com verbos (in)transitivos (cf. (21)):

(20) Eu acho que o povo brasileiro ele tem uma grave doença. $(\mathrm{PB} / * \mathrm{PE})$

(21) O Pedro, leu ele o livro. (*PB/PE)

(COSTA; GALVES, 2002, p. 115-118)

Duarte (2000, p. 27) defende que a emergência de construções com duplicação do sujeito e a não-produção de ordens VS com verbos (in)transitivos no PB evidenciam que essa língua está caminhando para se tornar uma língua não-pro-drop, como o francês, em virtude 
do enfraquecimento de sua morfologia de flexão verbal e, conseqüente, perda do Princípio Evite Pronome.

Segundo Britto (2000, p. 203), as construções com duplicação dos sujeitos no PB e no francês (cf. (22a) e (22b)) são similares ao que ocorre na ordem SV no PE (cf. (22c) ) ${ }^{6}$. À semelhança da análise de Barbosa (1996), é assumido que os sujeitos pré-verbais no PB estão deslocados à esquerda, estando adjungidos a IP e sendo duplicados por um pronome co-referente em Spec, IP:

(22) a. [XP DP [ipele [r, V (...)]]] (PB)

b. [XP DP [rP il [I, V (...)]]] (Francês)

c. [xp DP [IP pro $[\mathrm{r}, \mathrm{V}(\ldots)]]]$ (PE)

Adotando a proposta de Cardinaletti e Starke (1994) para a distinção dos pronomes em fortes e deficientes (fracos e clíticos), Kato (2000) e Britto (2000) argumentam que o pronome que duplica o sujeito no PB é um pronome fraco por poder sofrer redução fonológica (você $c \hat{e}$ ), possuir um antecedente proeminente no discurso que, nesse caso, é o sujeito à sua esquerda, não poder ocupar posições periféricas na frase, não poder ser coordenado e modificado, estando excluída a possibilidade de atribuição de um acento contrastivo sobre ele.

Seguindo a análise de Galves (1996), Kato (2000) argumenta que o PB não possui a categoria Agr independente em virtude do enfraquecimento de sua morfologia flexional, o que implica num sincretismo dessa categoria com T. Em línguas, como o espanhol, que possuem morfologia flexional rica, Agr é projetado, sendo o afixo de concordância uma espécie de pronome tal como defendido por Alexiadou e Anagnostopoulou (1998). Sob o ponto de vista de uma perspectiva minimalista, a autora sugere que Agr pronominal não vem preso ao verbo desde a numeração, sendo este flexionado apenas para tempo. Nessa

${ }^{6}$ Em Silva (2004), apresento argumentos contrários à análise de Britto (2000), pois evidências empíricas distinguem as construções de duplicação do sujeito em PB e em francês. Na primeira língua, os sujeitos duplicados não se encontram necessariamente deslocados à esquerda e, portanto, não estão deslocados à esquerda da frase, ao contrário da segunda língua. Para maiores detalhes, conferir também o artigo de Costa, Duarte e Silva (2005) publicado nesta revista. 
análise, Agr pronominal já aparece desde a base no núcleo $\mathrm{D}$ em Spec, VP como argumento do verbo, o que culmina na eliminação de pro referencial como uma categoria descritiva. Nesse sentido, Spec, TP não é projetado, tendo em vista que Agr pronominal merge com o verbo sob adjacência. Uma consequiência dessa análise é a seguinte: em construções com deslocamento à esquerda em línguas de sujeito nulo, não há pro ocupando a posição Spec, TP, mas o afixo pronominal adjungido a $\mathrm{T}$ é responsável para manter co-referência com o DP deslocado.

No desenvolver de sua análise, Kato (2000) também defende que os clíticos sujeitos no trentino e fiorentino encontram-se gerados no núcleo $\mathrm{D}$ em Spec, VP, não sendo necessário recorrer ao Agr pronominal, tendo em vista já funcionarem como um elemento de concordância. No inglês, ao contrário, Spec, TP é preenchido pelo DP sujeito, em virtude do enfraquecimento da morfologia flexional nessa língua ${ }^{7}$. Vale dizer que nessa proposta tanto o pronome fraco quanto os clíticos sujeitos e os afixos pronominais possuem traços-phi e de Caso. Sendo o traço-V de $\mathrm{T}$ forte, o verbo sobe até o núcleo dessa categoria funcional para checar esse traço; sendo o traço-D de $\mathrm{T}$ também forte, ele deve ser checado pelo pronome em Spec, TP no inglês, pelo clítico sujeito ou pelo afixo de concordância que merge com o verbo através de sua adjunção a $T$ no caso do trentino e do espanhol, respectivamente.

Contrariamente à análise de Kato (op. cit.), verifico que não só no PE (cf. COSTA, 2003), como também no PB, há motivação para serem projetadas as categorias funcionais AgrSP e TP na sintaxe, em virtude de os sujeitos não estarem em Spec, TP, mas na posição mais alta da frase. Ademais, assumirei com Bobaljik (1995) que em línguas, como o inglês, Spec, TP não está disponível para hospedar os sujeitos pré-verbais, ao contrário do islandês, o que vem corroborar a existência do Parâmetro Spec, TP formulado em (23):

7 A análise proposta por Kato para o inglês é similar ao que é proposto para $\mathrm{O} \mathrm{PB}$, sendo a única diferença a ausência do movimento do verbo para o núcleo flexional na sintaxe da primeira língua. 


\section{(23) The Spec, TP Parameter}

Some languages license Spec, TP as a potential landing site for the subject NP, other languages do not license this position $^{8}$ (BOBALJIK, 1995, p. 30).

Tal parâmetro ganha suporte explicativo quando verificada a morfologia de flexão verbal, valendo dizer, de antemão, que línguas em que Spec, TP não é licenciado, como é o caso do inglês, a componente morfológica atua como uma espécie de filtro sobre as derivações sintáticas, uma situação não prevista na análise de Kato (2000).

Comparando o paradigma flexional do islandês e do inglês conjugado no presente e no pretérito, Bobaljik observa que na primeira língua há razão para dizer que os morfemas T e Agr não estão em distribuição complementar em virtude de os morfemas de tempo - $\succsim i$ e $-\partial u$ co-ocorrerem com os morfemas de Agr $-r,-m$ e -ð no pretérito. No inglês, por sua vez, o morfema -ed que marca esse tempo e o morfema $-s$ indicador da terceira pessoa do singular no presente estão em distribuição complementar. Em outras palavras, sob a perspectiva teórica da Morfologia Distribuída (HALLE; MARANTZ, 1993), esses morfemas estão competindo para a sua inserção no mesmo nó terminal fornecido pela sintaxe à componente morfológica no inglês. Face à distinção entre essas línguas, o autor conclui: "[...] it appears that the presence of a marker of the past tense [in English] blocks insertion of an agreement marker. The lack of such competition in Icelandic suggests that there are at least two distinct nodes which may serve as the locus of vocabulary insertion"" (BOBALJIK, 1995, p. 25).

Levando em conta a distribuição complementar versus a não distribuição complementar dos morfemas Agr e $\mathrm{T}$ no inglês e no islandês, respectivamente, o autor verifica que, ao contrário da

8 O Parâmetro Spec, TP

Algumas línguas licenciam Spec, TP como um lugar potencial para o NP sujeito, outras línguas não licenciam esta posição - Tradução minha.

9 [...] parece que a presença de um morfema do tempo passado bloqueia a inserção de um morfema de concordância. A ausência de tal competição em islandês sugere que há pelo menos dois nós distintos que podem servir como o locus da inserção do vocabulário - Tradução minha. 


\section{VERBAIS NO PORTUGUÊS BRASILEIRO E NO PORTUGUÊS EUROPEU}

primeira língua, o islandês possui construções expletivas transitivas (Transitive Expletive Constructions (TECs) que servem como diagnóstico de que Spec, TP é licenciado obrigatoriamente. Nessas construções, o sujeito pode ocupar uma posição intermediária entre $\mathrm{o}$ verbo auxiliar e o verbo principal, precedendo advérbios como completamente que se encontram adjungidos ao VP, o que implica considerar que o sujeito está fora do VP e numa posição-A mais baixa do que Spec, AgrSP, nomeadamente Spec, TP:

(24) pað hefur sennilega einhver[vp alveg [vp lokið erkefninu]]. incubência

EXPL tem provavelmente alguém completamente terminado a

"Provavelmente alguém terminou a incubência completamente."

(JONAS; BOBALIK (1993 apud ALEXIADOU; GNOSTOPOULOU, 1998, p. 497))

Estando, portanto, em distribuição complementar os morfemas T e Agr no inglês, há motivação para que ocorra fusão na componente morfológica ou, mais precisamente, merger morfológico entre os nós sintáticos terminais. Essa operação de fusão só pode ocorrer entre nós irmãos, o que implica um processo de rearranjo desses nós para satisfazer o requisito da adjacência formulado em (25):

\section{(25) The Adjacency Condition}

In order for an affix and a stem to be combined, they must be adjacent. ${ }^{10}$

(BOBALJIK, op. cit., p. 57)

Um outro aspecto que vem corroborar a atuação da componente morfológica na gramática do inglês como uma espécie de filtro sobre as derivações sintáticas tem a ver com o movimento de Lowering de Ipara-V motivado nessa componente. Conforme já referido no início deste artigo, o inglês, ao contrário do francês, não possui movimento de verbos principais para o núcleo flexional na sintaxe, sendo uma das

10 A Condição de Adjacência:

Para um afixo e uma raiz serem combinados, eles devem ser adjacentes Tradução minha. 
evidências a impossibilidade de ocorrerem advérbios de VP entre o verbo e o argumento interno. Com base nisso, surge a pergunta: como os afixos flexionais estão presentes no núcleo verbal, já que este não se move para fora do VP?

Assumindo que a sintaxe manipula os traços da raiz verbal, bem como dos núcleos flexionais, Bobaljik propõe que, caso o movimento de núcleo a núcleo na sintaxe não seja permitido, os afixos flexionais são "fundidos" com a raiz verbal através do processo merger morfológico, uma operação que requer adjacência entre esses nós como já referido. Portanto, se houver um constituinte que rompa essa adjacência, como é o caso da negação no inglês, essa operação é bloqueada, utilizando-se como estratégia de último recurso a inserção do auxiliar DO que serve de suporte aos afixos flexionais, caso contrário a frase é agramatical.

Bobaljik pontua que, tanto numa análise que defenda $o$ movimento de V-para-I na sintaxe, como ocorre no francês com todos os tipos de verbos e no inglês apenas com os auxiliares (POLLOCK, 1989), quanto numa que assuma o movimento de V-para-I em LF (CHOMSKY, 1991), não há problemas quando a categoria NegP não intervém entre IP e VP. Contudo, o autor salienta que, por alguma razão, o alçamento no inglês de V-para-I em LF é bloqueado quando NegP está presente. Para solucionar esse problema o autor baseia sua análise no que é proposto por Halle e Marantz (1993). Indo de encontro à proposta de lowering sintático e do movimento de V-para-I em LF, esses autores argumentam que o nó afixal une-se à raiz verbal através de merge morfológico pelo fato de não haver elementos que rompam a adjacência entre esses nós. Nesse sentido, Lowering de Iparà-V é motivado na componente morfológica do inglês.

\subsection{Sujeitos pré-verbais estão em Spec, AgrSP no português brasileiro e no português europeu: contra-evidências à análise do deslocamento à esquerda dos sujeitos}

Nesta subseção, ao discorrer sobre a posição dos sujeitos préverbais no PE e no PB, assumo com Costa (1998) e Brito (2001) que esses sujeitos não estão deslocados à esquerda como propõem Barbosa (1996) e Barbosa, Duarte e Kato (2001) por ocuparem a posição-A Spec, IP. 
Contra-evidências à hipótese da adjunção do sujeito à categoria funcional IP formulada por Barbosa (op. cit) podem ser encontradas nas pesquisas de Costa (op. cit.) e Costa e Galves (2002), por exemplo. Comparando o comportamento dos sujeitos pré-verbais do $\mathrm{PB}$ e do PE com o de línguas, como o espanhol, o italiano e o grego, é plausível assumir que nestas os sujeitos encontram-se deslocados à esquerda por não possuírem propriedades- $\mathrm{A}$, ao contrário daquelas consoante as evidências que se seguem. Vale pontuar que amplio os argumentos empíricos de Costa (op. cit.) do PE para o PB:

A) Presença de ligação-A:

(26) a. Todos os estudantes pensam que eles passarão. (OKPE OKPB)

b. Todos os estudantes pensam que passarão eles. (OKPE $* \mathrm{~PB}^{11}$ )

(COSTA, op. cit., p. 328)

Frases como as de (26a) contrariam a análise de Barbosa (1996) que assume que a única posição-A no $\mathrm{PE}$ é $\mathrm{Spec}, \mathrm{VP}$, estando o sujeito pré-verbal ligado obrigatoriamente a uma categoria pronominal vazia nessa posição.

Outro argumento apresentado por Costa diz respeito aos casos em que a ligação-A pode ser estabelecida entre o sujeito pré-verbal e uma anáfora contida num PP adjunto na posição pré-verbal. Nesses casos, a idéia defendida por Barbosa (op. cit.) de que o sujeito préverbal obrigatoriamente se liga a uma categoria pronominal vazia em Spec, VP também não é atestada:

(27) Todos os coelhos $_{i}$, durante a sua $a_{i}$ refeição, comeram uma cenoura. (OKPE OKPB)

(COSTA, 1998, p. 111)

11 Embora o PB compartilhe com o PE o fato de a ordem não-marcada ser SVO, ao contrário do grego, ordens com o sujeito posposto não são produzidas no PB em virtude do processo de mudança por que está passando seu paradigma de flexão verbal, o que tem ocasionado um aumento substancial do preenchimento da posição pré-verbal do sujeito (DUARTE, 2000). 
B) Contexto marcado de topicalização múltipla:

(28)a. Sobre o tempo, falei com o Pedro. (OKPE OKPB)

b. Sobre o tempo, com o Pedro, falei. (?/??PE ?/??PB)

No caso de o DP O Pedro vir seguido do constituinte topicalizado Com a Maria, a frase torna-se muito marginal (cf. (29a)), contudo, se for retomado por um DP interno à frase, esta se torna aceitável (29b), o que caracteriza uma construção com Deslocação à Esquerda do Tópico Pendente:

(29) a. O Pedro, com a Maria, falou rapidamente. (??PE ??PB)

b.O Pedro, com a Maria, esse sacana falou rapidamente. (?PE ?PB)

C) SVO em contexto não-marcado:

A ordem SVO é a ordem não-marcada no PE, tendo em vista ser a ordem legítima numa pergunta com focalização de toda a frase como: $O$ que é que aconteceu?:

(30) A: O que é que aconteceu?

B: a. O João partiu um copo. (OKPE OKPB)

a'. *Partiu o João um copo. (*PE *PB)

(COSTA; GALVES, 2002, p. 118)

Rediscutindo a proposta de Barbosa (1996) de que a única posição-A para os sujeitos em PE é Spec, VP, Costa e Galves argumentam que tal análise não é confirmada. Se essa posição fosse, de fato, a única posição-A, o sujeito apareceria posposto ao verbo na resposta a pergunta em (30).

D) Ausência de efeitos de definitude na posição pré-verbal:

DPs pré-verbais indefinidos no PE e no PB podem possuir leitura partitiva e não-partitiva, ao contrário do grego:

(31) Alguém cumprimentou a Maria. (leitura (+partitiva) ou (partitiva))

Assumindo que no grego sujeitos pré-verbais estão deslocados à esquerda e que no PE e no PB estão em Spec, IP, concluo que a checagem do traço EPP dá-se de forma diferenciada: na primeira, via movimento do verbo e, nas segundas, por Move ou Merge de um XP, 
uma situação não prevista na análise de Alexiadou e Anagnostopoulou (1998).

Levando em conta que advérbios com leitura orientada para o sujeito sempre estão adjungidos a TP (cf. (32a)), Costa (2003, p. 39) propõe que o DP sujeito encontra-se em AgrSP em virtude de a adjacência entre ele e o verbo ser rompida. Do contrário, tendo esse advérbio leitura de modo, como já referido, ele estará em posição pósverbal necessariamente (cf. (32b) e (32c)):

(32)a. O João estupidamente entornou o café. (OKPE OKPB)

b. O João entornou estupidamente o café. (OKPE OKPB)

c. O João entornou o café estupidamente. (OKPE OKPB)

Em contextos de tópicos marcados, quando o sujeito está deslocado à esquerda e é retomado por uma categoria pronominal no domínio interno da frase, o autor observa que a frase em que o advérbio rompe a adjacência entre esses constituintes é agramatical, o que implica considerar que Spec, TP não é uma posição disponível para hospedar os sujeitos em contextos declarativos:

(33)a. O João... ele estupidamente entornou o café.

b. *O João... estupidamente ele entornou o café.

Evidência adicional de que Spec, TP não é uma posição disponível para hospedar os sujeitos pré-verbais no PB também pode ser encontrada em construções com duplicação do sujeito. Nesses casos, advérbios orientados para o sujeito como intencionalmente e o advérbio sempre adjungidos a TP não podem romper a adjacência entre o DP sujeito e o pronome que o duplica ${ }^{12}$, o que me leva, portanto, a formulação da configuração sintática em (35) em que o sujeito encontra-se em Spec, AgrSP e o verbo movimenta-se até T:

(34)a. ?*O João (intencionalmente/sempre) ele beijou a Maria.

$\mathrm{a}^{\prime}$. O João ele (intencionalmente/sempre) beijou a Maria.

(35) AgrSP $\left.\left._{\text {DP }} \mathrm{DP}_{\mathrm{i}}\left[\mathrm{TP} \mathrm{t}_{\mathrm{i}}\left[\mathrm{T}, \mathrm{V}_{\mathrm{j}}\left[\mathrm{VP} \mathrm{t}_{\mathrm{i}}\left[\mathrm{v}, \mathrm{t}_{\mathrm{j}} \mathrm{DP}\right]\right]\right]\right]\right]\right]$

12 Agradeço aos falantes do PB que me forneceram seus julgamentos de gramaticalidade das frases. 
Retomando ao fato de Spec, TP não ser uma posição-A disponível para hospedar os sujeitos pré-verbais no $\mathrm{PE}$ e no $\mathrm{PB}$ e já que essas línguas têm movimento curto de V-para-T, como é possível estabelecer adjacência entre os núcleos Agr e $\mathrm{T}$ nessa língua? Fundamentada no arcabouço teórico da Morfologia Distribuída (HALLE; MARANTZ, 1993) e, assumindo a proposta de Bobaljik (1995) sobre a existência do Parâmetro Spec, TP na Gramática Universal e seguindo a análise de Costa (2003, p. 45) para o PE, observo que, não só nessa língua, como também no $\mathrm{PB}$, os morfemas T e Agr, à semelhança do inglês, competem para a inserção num único nó terminal fornecido pela sintaxe à componente morfológica, o que implica dizer que a morfologia atua sobre as derivações sintáticas (ex. do paradigma verbal do PE no presente do indicativo: fale-i/ fala-ste/ falo-u/ falá-mos/ fala-stes/ fala-ram). Nessa acepção, já que os morfemas Agr e T co-ocorrem amalgamados, havendo movimento curto de V-para-T, há motivação na componente morfológica para Lowering de Agr-para-T.

(36)Sintaxe propriamente dita

(Raising de V-para-T)

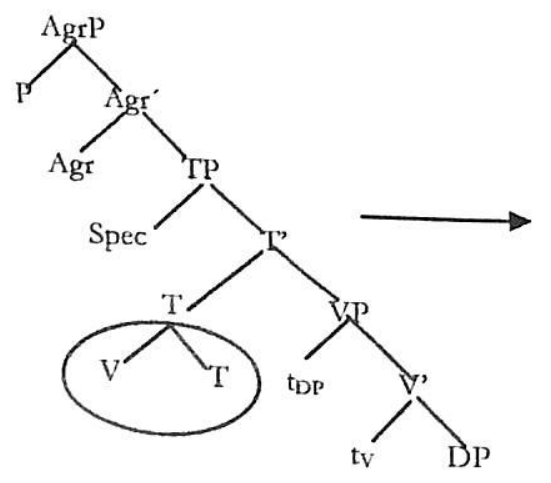

Componente morfológica (Lowering de Agr-para-T)

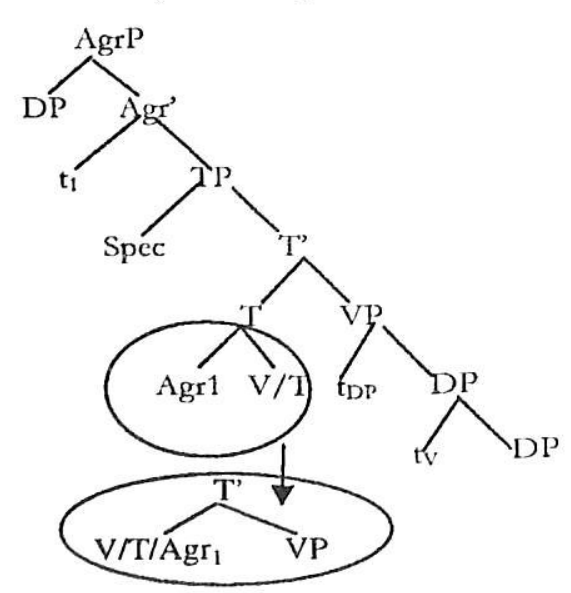

É válido relembrar que a fusão de Agr e T através da merger morfológico só é possível em (36) em virtude de não haver constituinte interveniente entre Agr e T. Caso o sujeito estivesse em Spec, TP no PE e no PB, ele bloquearia essa adjacência, com exceção dos advérbios, conforme verifica Bobaljik (1995). 


\section{Conclusão}

Ao discorrer inicialmente sobre o movimento do verbo na sintaxe de algumas línguas particulares, foi possível evidenciar que, no PE e no PB, há movimento curto de V-para-T. Ademais, ao centrar minha atenção no posicionamento dos sujeitos pré-verbais em sentenças declarativas finitas, foi plausível argumentar, por um lado, que sujeitos pré-verbais estão em Spec, AgrSP nessas línguas e, por outro, que a morfologia atua sobre as derivações sintáticas seguindo a linha de raciocínio de Bobaljik (1995). Em ambas as línguas, já que os morfemas Agr e T co-ocorrem amalgamados, Lowering de Agr-para$T$ é motivado na componente morfológica, a fim de que os nós terminais, que estão em competição para a inserção num mesmo nó terminal, sejam fundidos, em satisfação à condição de adjacência. Uma das conseqüências substanciais dessa análise é que a existência do Parâmetro EPP formulado por Alexiadou e Anagnostopoulou (1998) pode ser refutada.

\section{Referências}

ALEXIADOU, A.; ANAGNOSTOPOULOU, E. Parametrizing AGR: Word Order, V-movement and EPP-checking. Natural Language and Linguistic Theory, n. 16, p. 491-539, 1998.

BARBOSA, P. A New Look at the Null Subject Parameter. Paper presented at CONSOLE III, Venice. 1994.

BARBOSA, Pilar. A New Look at the Null Subject Parameter. In: COSTA, J. et al (Eds.). Proceedings of ConSOLE IV, Leiden, Nov. 1996. p. 375-395.

BARBOSA, P.; DUARTE, E. L.; KATO, M. A. A Distribuição do Sujeito Nulo no Português Europeu e no Português Brasileiro. In: CORREIA, C. N.; GONÇALVES, A. Actas do XVI Encontro Nacional da Associação Portuguesa de Lingüística. Lisboa: Colibri Artes Gráficas, 2001. p. 539-550.

BELLETTI, A. Generalized Verb Movement. Turin: Rosenberg e Sellier, 1990.

BOBALJIK, J. D. Morphosyntax: The Syntax of Verbal Inflection. MIT Working Papers in Linguistics. Cambridge: Massachusetts, 1995. 
BRITO, A. M. Clause Structure, Subject Positions and Verb Movement about the Positions of sempre in European Portuguese and Brazilian Portuguese. In: D'HULST, Y. et al. (Eds.). Current Issues in Linguistic Theory. Amsterdam, Philadelphia: John Benjamins Publishing Company, 2001. p. 63-85.

BRITTO, H. Syntactic Codification of Categorical and Thetic Juggments in Brazilian Portuguese. In: KATO, M. A.; NEGRÃO, E. V. (Eds.). Brazilian Portuguese and the Null Subject Parameter. Madrid: Iberoamericana, 2000. p. 195-222.

CARDINALETTI, A; STARKE, M. The Typology of Structural Deficiency. On the Three Grammatical Classes. January, 1993, May 1994. p. 1-52.

CHOMSKY, N. Some Notes on Economy of Derivation and Representation. In: FREIDEN, R. (Ed.). Principle and Parameters in Comparative Grammar. Cambridge, Mass.: MIT Press, 1991. p. 417 454.

CINQUE, G. On the Theory of Relative Clauses and Markeness. The Linguistic Review 1, 1982. p. 247-294.

COSTA, J. Word Order Variation: A Constraint-Based Approach. Holanda: Holland Academic Graphics, 1998.

COSTA, J. Null vs Overt Spec, TP in European Portuguese. In: QUER J. et alii (Eds.). Romance Languages and Linguistic Theory 2001: Selected papers from 'Going Romance'. Amsterdam: John Benjamins, 2003. p. 33-49.

DUARTE, M. E. L. The Loss of the 'Avoid Pronoum' Principle in Brazilian Portuguese. In: KATO, M. A.; NEGRÃO, E. V. (Eds.). Brazilian Portuguese and the Null Subject Parameter. Madrid: Iberoamericana, 2000. p. 17-36.

GALVES, C. O Enfraquecimento da Concordância no Português Brasileiro. In: ROBERTS, I.; KATO, M. A. (Org.). Português brasileiro: Uma Viagem Diacrônica. 2. ed. São Paulo: UNICAMP, 1996. p. 387-408.

GALVES, C. Tópicos, sujeitos, pronomes e concordância no português brasileiro. Cadernos de Estudos Lingüísticos, n. 47, p. 1931, Jan./ Jun. 1998. 
HALLE, M.; MARANTZ, A. Distributed Morphology and The Pieces of Inflection. In: HALE, K.; KEYSER, S. J. (Eds.). The View from Building 20: Essays in Linguistics in Honor of Sylvain Bromberger. Current Studies in Linguistics, 24, Cambridge, Massachusetts: The MIT Press, 1993. p. 111-176.

JONAS, D.; BOBALJIK, J. Specs for Subjects. MIT Working Papers, 18, p. 59-98. 1993.

KATO, M. A. A Restrição de Monoargumentalidade da Ordem VS no Português do Brasil. Fórum Lingüístico. Florianópolis, Pós-graduação em Linguística, UFSC, 1999, p. 1-21. (no prelo)

KATO, M. A. The Partial Pro-drop Nature and the Restricted VS Order in Brazilian Portuguese. In: KATO, M. A.; NEGRÃO, E. V. (Eds.). Brazilian Portuguese and the Null Subject Parameter. Madrid: Vervuert, Iberoamericana, 2000. p. 223-258.

MAY, R. Logical Form. Cambridge, Massachusetts: MIT Press, 1985. PONTES, E. Sujeito : da Sintaxe ao Discurso. São Paulo: Ática; Brasília, INL, 1986.

POLLOCK, J. Verb Movement, Universal Grammar, and the Structure of IP. Linguistic Inquiry, n. 20, v. 3, p. 365-424, 1989.

RIZZI, L. A Parametric Approach to Comparative Syntax: Properties on the Pronominal System. HAEGEMAN, L. (Ed.). The New Comparative Syntax. London, New York: Longman, 1997. p. 268285.

SILVA, C. R. T. As Implicações da Natureza de AGR para a Ordem VS: um Estudo Comparativo entre o Português Brasileiro $e o$ Português Europeu. Tese de Doutorado em Linguística. Maceió: Universidade Federal de Alagoas, 2004.

VIKNER, S. $\mathrm{V}^{0}$-to- $\mathrm{I}^{0}$ movement and inflection for person in all tenses. In: HAEGMAN, L. (Ed.). The New Comparative Syntax. London, New York: Longman, 1997. p. 189-213. 